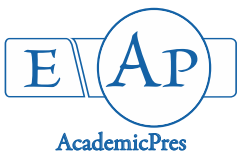

Akinropo MS et al. (2020)

Notulae Scientia Biologicae 12(1):74-89

DOI: $10.15835 / \mathrm{nsb} 12110604$

Research Article

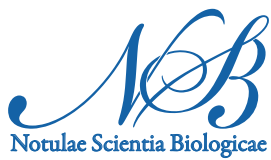

\title{
In vitro callus and shoot regeneration in Enterolobium cyclocarpum (Jacq.) Grised. - a fast timber yielding species
}

\author{
Michael S. AKINROPO*, Benjamin E. AYISIRE, Ejeoghene R. OGBIMI
}

Obafemi Awolowo University, Department of Botany, Ile-Ife, Osun State, Nigeria; mickoseun@yahoo.com (*orrespondingauthor)

\begin{abstract}
This study was conducted to investigate the in vitro callus induction and rapid shoot regeneration potential in Enterolobium cyclocarpum, a plant native to central Mexico but widely introduced into Africa. The leaf, stem and nodal explants of E. cyclocarpum were cultured on full strength Murashige and Skoog (MS) medium supplemented with different concentrations of Cytokinins - Benzyladenine (BA) and/or Kinetin and Auxins - Naphthalene acetic acid (NAA) and/or 2,4-Dichlorophenoxylacetic acid (2,4-D) each alone and in combination. The leaf explants did not respond to these treatments. The Nodal explants were best for caulogenesis, while the explant responses were in the order- nodal $>$ stem $>$ cotyledon for callogenesis in MS medium supplemented with BA and/or Kin combined with NAA and/or 2,4-D. The varied combinations induced white compact callus. The highest callus production was observed on MS medium supplemented with $2.7 \mu \mathrm{M} \mathrm{NAA}+2.2 \mu \mathrm{M} \mathrm{BA}$ and 5.4 $\mu \mathrm{M} \mathrm{NAA}$ alone. Nodal and cotyledon explants developed callus and multiple shoots on MS supplemented with a combination of cytokinin (BA and/or Kin.) and auxin (NAA and/or 2,4-D). The maximum number of $3.98 \pm 0.37$ and $2.1 \pm 0.11$ shoots/explants were recorded for nodal and cotyledon explants on MS medium supplemented with a combination of $8.8 \mu \mathrm{M} \mathrm{BA}+2.7 \mu \mathrm{M}$ NAA and $2.2 \mu \mathrm{M} \mathrm{BA}+2.7 \mu \mathrm{M}$ NAA respectively. On the basal medium, $10 \%$ of the excised shoots rooted successfully. Thus, this in vitro method can be exploited for conservation and mass propagation of this fast timber yielding tree and also utilized for embryogenesis studies.
\end{abstract}

Keywords: callus; caulogenesis; callogenesis; explants; multiple shoots

\section{Introduction}

The anthropogenic deforestation occurring throughout the world has always been increasing, with an alarming rate in the last 3 decades in particular in West Africa primarily due to urbanization, unsustainable logging, agricultural farming and collection of fuel wood (FOMERCU, 1999; Sayer $e t$ al., 2010). The gradual increase in deforestation practices for economic and/or social reasons without any simultaneous replanting is a global threat to the sustainability of the environment (FAO, 2005; Odediran et al., 2013). Africa has the second highest rate of tropical deforestation in the world. The tropical forests in this region have declined at an annual rate of 3.4 million hectares between 2000 and 2010 because of degradation and deforestation processes (FAO, 2010; Eleanya, 2014). 
Nigeria, alone lost a range between 3.5 to $3.7 \%$ of forest land per annum (Ladipo, 2010; UN-REDD, 2013;). Attendant consequences of deforestation are erosion, flooding, global warming, loss of habitat for earth's land animals and plants and not the least desertification (Farinola et al., 2013). In order to mitigate these consequences, reforestation is urgently needed and this can be done by introducing fast-growing tree species such as Enterolobium cyclocarpum.

Enterolobium is an exotic species introduced to Nigeria and other tropical regions (Ezenwa, 1999; Rodríguez-Sahagún et al., 2007). It is native to tropical America, where it is among the most invaluable and majestic tree tolerant of a wide range of rainfall level, temperature and soil condition. E. cyclocarpum is naturally distributed from western and central Mexico to the northern part of South America (Neimbro-Rocas et al., 2003). E. cyclocarpum usually called monkey ear or ear pod tree belongs to the family Fabaceae. The genus Enterolobium contains only five species, all native to South and Central America. E. cyclocarpum is the only widely distributed and is the national tree of Costa Rica and prized for its ornamental, timber and large feathery shady relief from the intensity of the sun. It is a semi-deciduous, medium- to large-sized, and fast-growing tree species reaching about 35-50 m in height, wide spread of about $35 \mathrm{~m}$ or more (Rodríguez-Sahagún et al., 2007). The trunk is branched with many stems, with light gray bark, and with prominent dark brown vertical fissure.

The tree crown is broader and widely spreading especially those that reach canopy (Figures 1 and 2). The bipinnate compound leaves are alternate, $15-40 \mathrm{~cm}$ in length, with $20-25$ leaflets. The inflorescent consists of fragrant, white flowers, with about 20 filamentous stamens, as its main features, and a single pistil bounded together by a short green corolla and calyx. (Neimbro-Rocas et al., 2003; Harmon, 2008; Pier, 2008).

The fruits are flattened, glossy, dark-brown indehiscent pod, shaped like an orbicular disk (Figures 3 and 4). The pod contains about 8-16 radially arrange seeds. The seed is hard-coated resembling small stone in strength and durability, which avoids germination until a structural modification (scarification) allows the hydration of the embryo. Enterolobium seeds are big, red-brown and marked with a conspicuous light brown ring. Seed are rich in protein (about 35\%) and amino acid (Rodríguez-Sahagún et al., 2007). They also contain iron, calcium, Phosphorus and ascorbic acid (Harmon, 2009). Also, seeds and bark contain tannins (Barwick, 2004).

The wood of E. cyclocarpum is lightweight and is resistant to termite attack (Uphof, 1959; Standley and Steyermark, 1976), which makes it feasible for house construction, furniture and shipbuilding (NiembroRocas, 2003; Rodríguez-Sahagún et al., 2007). It is also useful as firewood due to its high caloric content (Rodríguez-Sahagún et al., 2007). It is widely grown as a shade tree to shelter plantation, livestock, even its fruits and leaves are used as fodder directly from the tree or as a nutritional complement (Carranza-Montaño et al., 2003; Mota et al., 2005). Syrup and gum obtained from the bark and truck respectively are used in the treatment of colds and medicine for chest affections (Uphof, 1959; Burkil, 2004).

In Mexico, the boiled seeds are consumed in sauces, soups and as a coffee substitute, and several medicinal properties have been attributed to them (Carranza-Montaño et al., 2003; Niembro-Rocas, 2003). Moreover, several biotechnological applications such as its gum as a fungi culture substrate or for the production of ice cream and yogurt have recently been proposed for this tree species (Rincón et al., 2005, 2006).

The conventional method of propagating E. cyclocarpum is mainly sexual i.e from seeds. However, the regeneration rate of most leguminous trees in natural habitats is low due to seed dormancy (Nanda et al., 2004). This limitation consequently affects the germination rate and the death of young seedlings under natural conditions. The conventional method of propagation cannot meet the need for forest restoration programs, hence micropropagation, is required.

To date, micropropagation offers a rapid means for reforestation, multiplying woody biomass and for conserving elite and rare germplasm (Xie and Hong, 2001). There is limited information on in vitro techniques of propagating E. cyclocarpum. Rodríguez-Sahagún et al. (2007) in Mexico has used nodal segments and apical segment from axenic seedlings were cultured on MS basal medium supplemented naphthaleneacetic acid 
76

(NAA) in combination with benzyl adenine (BA) or kinetin (KIN). They reported multiple shoot induction using nodal segment collected from in vitro germinated seedling when cultured on MS medium was supplemented with combination BA and NAA. However, E. cycocarpum as an established exotic species to Nigeria, little or no studies had been done on it in vitro propagation.

Thus, the objective of this study was to evaluate the effects of Cytokinin-BA and Auxin- NAA on multiple shoot induction using ex vitro explants of leaf, stem and node of E. cyclocarpum - a protocol needed for the mass propagation as well as genetic improvement programs.
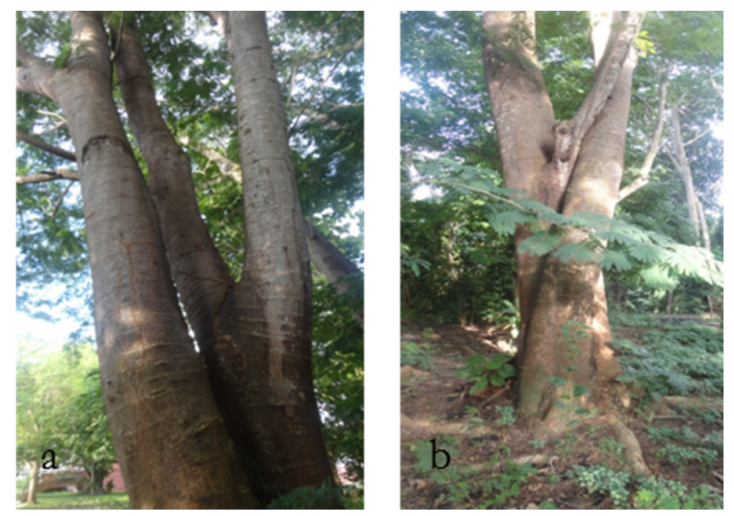

Figure 1. Habit of Enterolobium cyclocarpum tree
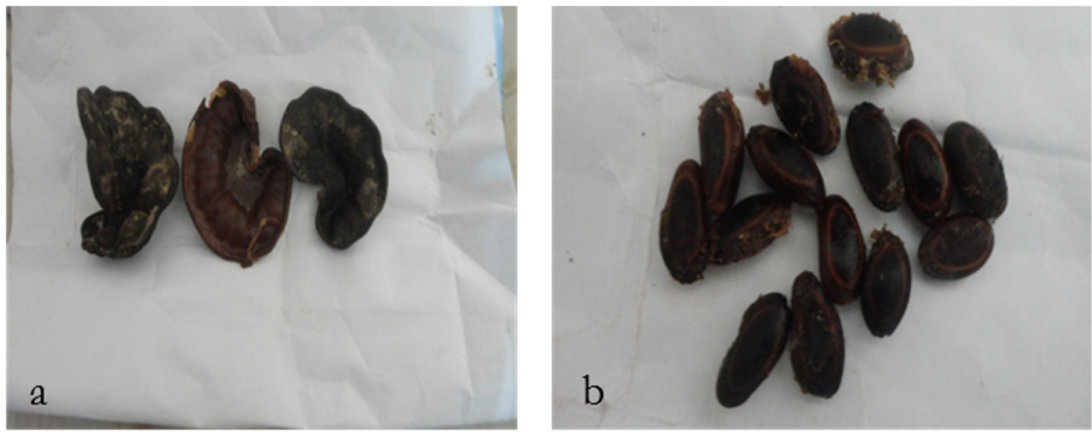

Figure 2. Ear pod fruits (a) and the hard-coated seeds (b)

\section{Materials and Methods}

\section{Plant materials}

The seeds of E. cyclocarpum were obtained from indehisced pods collected from an actively growing tree in Reforestation Garden of Botany, Department of Botany, Obafemi Awolowo University, Ile - Ife. Seeds were selected based on their non-dehised seed coat, scarified using emery paper. The scarified seed was surface sterilized using $10 \% \mathrm{NaOCl}$ for 15 minutes, and then kept under running tap water for $30 \mathrm{~min}$. Then they were soaked in distilled water for 15 mins to allow for imbibition. Finally, the seeds were planted in petri- dishes for 2 weeks before they were transferred to top soil and were out in a randomized environment in which they can access various environmental factors.

\section{Explant source and sterilization}

The leaf, stem and node ex vitro explants of E. cyclocarpum were obtained from 3-8 weeks old seedlings and were kept under running water for 10-15 minutes before culturing. 
Media and culture of explants

The explants were cultured on full strength MS (Murashige and Skoog, 1992) basal medium containing $3 \%$ sucrose per liter. The $\mathrm{pH}$ of the media was adjusted to $5.7 \pm 0.02$ with $1 \mathrm{~N} \mathrm{NaOH}$ or $1 \mathrm{~N} \mathrm{HCl}$ solutions, solidified with $0.8 \%$ agar (BDH) per liter prior to autoclaving at $121^{\circ} \mathrm{C}$ and $103 \mathrm{kpa}$ for 15 minutes. The basal medium alone served as control and was also supplemented with cytokinin separately and/or with auxins.

The leaf, stem and Nodal explants were disinfected with $70 \%$ ethanol for 3-4 minutes and surface sterilized by washing with $10 \% \mathrm{NaOCl}$ containing two drops liquid detergent (tween-20) for 15 minutes after which they were rinsed in at least three changes of sterile distilled water. The leaf explants were sectioned to about $10 \mathrm{~mm}^{2}$ in size while the stem and the node were about $10 \mathrm{~mm}$ in length. The explants were cultured in $15 \mathrm{~cm}^{3}$ test tube containing $8 \mathrm{ml}$ of the culture medium. The leaf explants were cultured with the adaxial surface in contact with the medium while the nodes and stem cutting were slantingly explanted on the medium.

\section{Culture conditions}

The culture tubes were covered with non-adsorbent cotton wool and wrapped with aluminum foil, after which they were incubated at a temperature of $25 \pm 2{ }^{\circ} \mathrm{C}$ and a photoperiod of $16 \mathrm{~h}$ light with cool white fluorescent light $\left(20 \mu \mathrm{mol} \mathrm{m} \mathrm{m}^{-2}\right)$.

\section{Statistical analysis}

The data in terms of the number of induced shoot buds, shoot length, callus induction, morphology, and colour of callus were recorded after 4-5 weeks in culture. Each treatment consisted of 10 replicates and all experiments were repeated twice. The data were analyzed statistically using standard error (S.E) of the mean and were separated using Duncan Multiple Range Test (DMRT). All statistical analyses were performed with Statistical Package for Social Sciences (SPSS, version 11.5).

\section{Results}

There was no callus initiation with the cotyledon explants of E. cyclocarpum cultured in the MS medium alone i.e. the control. Initiation of callus was observed within 2 weeks in the cotyledon explants on MS media containing low concentrations of auxin alone or their various concentrations combined with the cytokinins. The proliferation rate of callus induced from the cotyledon explants was generally slow. Shoot bud formation became evident from the scanty callus induced by some auxin / cytokinin combinations after 3 weeks of culture (Figure 3a).

A maximum mean number of 2.1 shoots per explant was observed with cotyledon explants grown on MS medium containing $2.7 \mu \mathrm{M} N A A+2.2 \mu \mathrm{M}$ BA which also induced the highest frequency $(58.47 \pm 1.19 \%)$ of callus formation (Tables 1 and 3 ). The concentration of $2.7 \mu \mathrm{M}$ NAA $+4.7 \mu \mathrm{M}$ kinetin in its case induced highest frequency $(51.57 \pm 1.88 \%)$ of off white callus (Table 5) and the highest mean number of 1.5 shoots/explant although this was not significantly $(\mathrm{p} \leq 0.05)$ different from 1.4 shoots/explant induced from cotyledon explants cultured on MS medium containing $2.7 \mu \mathrm{M} \mathrm{NAA}+2.35 \mu \mathrm{M}$ kinetin (Tables 2, 4 and 5). Little extension growth was shown by the shoot buds when subcultured. The shoot buds that formed from the cotyledon-derived callus on MS medium supported with $2.7 \mu \mathrm{M} \mathrm{NAA}+4.7 \mu \mathrm{M}$ BA developed further when subcultured, $40 \%$ of the shoots produced thick roots in MS hormonal free medium forming complete plantlets. 


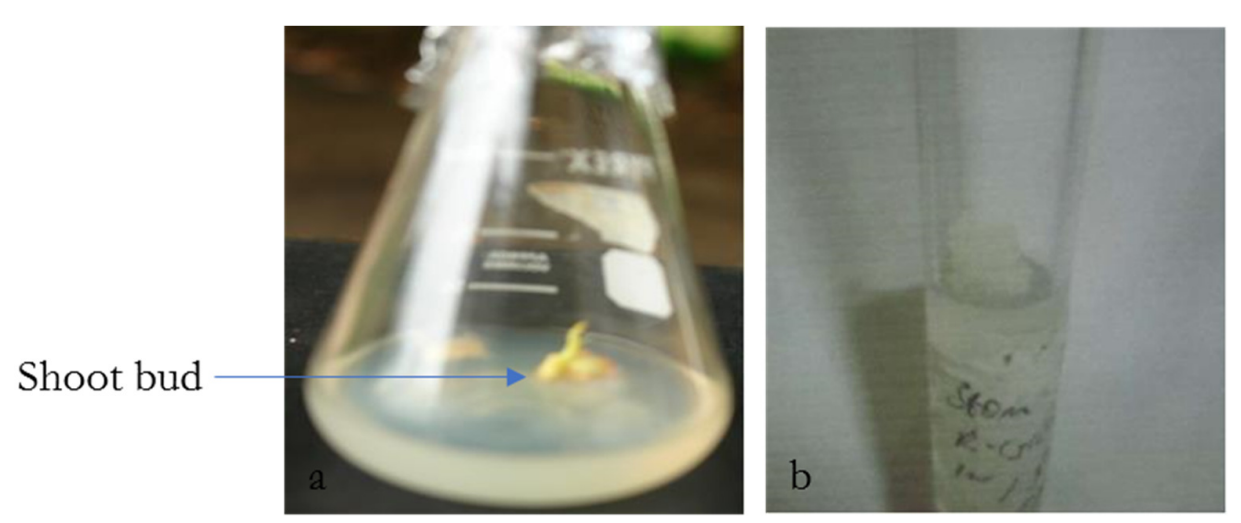

Figure 3. Scanty (with shoot bud) and compact callus induced from cotyledon and stem explant of $E$. cyclocarpum after three weeks of culture respectively on MS medium supplemented with 4.5 $\mu \mathrm{M} 2$, 4-D + $9.4 \mu \mathrm{M}$ Kinetin (a) and $5.4 \mu \mathrm{M}$ NAA alone (b)

Table 1. The effects of various concentrations of NAA, 2,4-D alone or each separately combined with BA

\begin{tabular}{|c|c|c|c|c|c|c|}
\hline \multirow[t]{2}{*}{$\mathrm{S} / \mathrm{N}$} & \multicolumn{3}{|c|}{$\begin{array}{l}\text { MS medium + PGR } \\
\text { concentration }(\mu \mathrm{M})\end{array}$} & \multirow{2}{*}{$\begin{array}{c}\text { \% response of } \\
\text { cotyledon explant } \\
(\text { mean } \pm \text { S.E })\end{array}$} & \multirow{2}{*}{$\begin{array}{c}\% \text { response of } \\
\text { nodal explant } \\
(\text { mean } \pm \text { S.E })\end{array}$} & \multirow{2}{*}{$\begin{array}{l}\text { \% response of } \\
\text { stem explant } \\
(\text { mean } \pm \text { S.E })\end{array}$} \\
\hline & $\mathrm{BA}$ & NAA & $2,4-\mathrm{D}$ & & & \\
\hline 1. & - & - & - & $0.00 \pm 0.00^{\mathrm{a}}$ & $0.000 \pm 0.00^{\mathrm{a}}$ & $0.00 \pm 0.00^{\mathrm{a}}$ \\
\hline 2. & - & - & 2.25 & $34.59 \pm 3.01^{\mathrm{cd}}$ & $48.47 \pm 1.099^{\text {cde }}$ & $43.80 \pm 2.50^{\text {defg }}$ \\
\hline 3. & - & - & 4.5 & $34.22 \pm 3.62^{\text {cde }}$ & $43.40 \pm 1.47^{\mathrm{bc}}$ & $48.10 \pm 4.31^{\mathrm{eg}}$ \\
\hline 4. & - & - & 9.0 & $0.00 \pm 0.00^{\mathrm{a}}$ & $39.73 \pm 1.88^{\mathrm{b}}$ & $41.60 \pm 2.31^{\text {cdef }}$ \\
\hline 5. & - & 2.7 & - & $33.23 \pm 3.50^{\mathrm{cd}}$ & $55.37 \pm 4.33^{\mathrm{e}}$ & $44.37 \pm 3.14^{\mathrm{de}}$ \\
\hline 6. & - & 5.4 & - & $42.34 \pm 4.00^{\mathrm{ef}}$ & $51.43 \pm 2.38^{\mathrm{de}}$ & $51.83 \pm 5.811^{\mathrm{efg}}$ \\
\hline 7. & - & 10.8 & - & $0.00 \pm 0.00^{\mathrm{a}}$ & $48.13 \pm 1.40^{\text {cd }}$ & $32.17 \pm 5.97^{b}$ \\
\hline 8. & 2.2 & - & - & $0.00 \pm 0.00^{\mathrm{a}}$ & $66.67 \pm 2.14^{\mathrm{f}}$ & $0.00 \pm 0.00^{\mathrm{a}}$ \\
\hline 9. & 2.2 & - & 2.25 & $29.76 \pm 0.68^{b c}$ & $74.50 \pm 2.05^{\text {ghijk }}$ & $45.83 \pm 4.54^{\mathrm{de}}$ \\
\hline 10. & 2.2 & - & 4.5 & $40.5 \pm 2.22^{\mathrm{def}}$ & $75.27 \pm 2.30^{\text {ghijk }}$ & $33.63 \pm 3.80^{b c}$ \\
\hline 11. & 2.2 & - & 9.0 & $35.23 \pm 3.30^{\text {cdef }}$ & $68.67 \pm 1.54^{\mathrm{fgh}}$ & $25.97 \pm 2.41^{\mathrm{b}}$ \\
\hline 12. & 2.2 & 2.7 & - & $58.47 \pm 1.19^{\mathrm{g}}$ & $81.57 \pm 1.92^{\mathrm{k}}$ & $62.33 \mathrm{i} \pm 3.49^{\mathrm{h}}$ \\
\hline 13. & 2.2 & 5.4 & - & $43.09 \pm 2.14^{\mathrm{f}}$ & $80.60 \pm 2.19^{\mathrm{jk}}$ & $69.60 \pm 1.54^{\mathrm{ij}}$ \\
\hline 14. & 2.2 & 10.8 & - & $40.44 \pm 2.94^{\mathrm{def}}$ & $75.80 \pm 3.23^{\text {hijk }}$ & $66.70 \pm 3.30^{\text {hij }}$ \\
\hline 15. & 4.4 & - & - & $0.00 \pm 0.00^{\mathrm{a}}$ & $71.90 \pm 1.96^{\text {fghi }}$ & $0.00 \pm 0.00^{\mathrm{a}}$ \\
\hline 16. & 4.4 & - & 2.25 & $31.14 \pm 3.45^{\mathrm{c}}$ & $80.57 \pm 1.25^{\mathrm{jk}}$ & $35.77 \pm 3.84^{\mathrm{bcd}}$ \\
\hline 17. & 4.4 & - & 4.5 & $34.24 \pm 3.56^{\mathrm{cd}}$ & $76.10 \pm 2.81^{\mathrm{hijk}}$ & $32.13 \pm 2.40^{\mathrm{b}}$ \\
\hline 18. & 4.4 & - & 9.0 & $22.32 \pm 2.71^{b}$ & $75.20 \pm 2.84^{\text {ghijk }}$ & $0.00 \pm 0.00^{\mathrm{a}}$ \\
\hline 19. & 4.4 & 2.7 & - & $41.24 \pm 3.49^{\mathrm{dcf}}$ & $76.10 \pm 2.81^{\mathrm{hijk}}$ & $73.03 \pm 3.58^{j k}$ \\
\hline 20. & 4.4 & 5.4 & - & $21.49 \pm 6.32^{\mathrm{def}}$ & $79.83 \pm 1.91^{\mathrm{jk}}$ & $82.20 \pm 2.63^{k}$ \\
\hline 21. & 4.4 & 10.8 & - & $23.54 \pm 2.10^{\mathrm{b}}$ & $73.23 \pm 1.8^{\text {fghij }}$ & $66.17 \pm 3.27^{\text {hij }}$ \\
\hline 22. & 8.8 & - & - & $0.00 \pm 0.00^{\mathrm{a}}$ & $70.43 \pm 2.77^{\text {fghi }}$ & $0.00 \pm 0.00^{\mathrm{a}}$ \\
\hline 23. & 8.8 & - & 2.25 & $30.84 \pm 2.05^{c}$ & $69.73 \pm 2.52^{\text {fghi }}$ & $35.67 \pm 2.94^{\mathrm{bcd}}$ \\
\hline 24. & 8.8 & - & 4.5 & $28.54 \pm 4.44^{c}$ & $68.90 \pm 2.59^{\text {fghi }}$ & $42.77 \pm 3.71^{\text {cde }}$ \\
\hline 25. & 8.8 & - & 9.0 & $0.00 \pm 0.00^{\mathrm{a}}$ & $67.50 \pm 2.04^{\mathrm{fg}}$ & $0.00 \pm 0.00^{\mathrm{a}}$ \\
\hline 26. & 8.8 & 2.7 & - & $29.53 \pm 3.54^{\mathrm{bc}}$ & $75.07 \pm 2.85^{\text {ghijk }}$ & $56.40 \pm 3.79^{\text {fgh }}$ \\
\hline 27. & 8.8 & 5.4 & - & $23.07 \pm 2.50^{\mathrm{b}}$ & $71.63 \pm 1.79^{\text {fghi }}$ & $59.57 \pm 5.088^{\text {ghi }}$ \\
\hline 28. & 8.8 & 10.8 & - & $22.34 \pm 2.15^{b}$ & $76.67 \pm 3.11^{\mathrm{ijk}}$ & $51.93 \pm 6.058^{\text {efg }}$ \\
\hline
\end{tabular}

on callus formation from cotyledon, stem and nodal explants of E. cyclocarpum 
PGR: Plant growth regulators; BA:Benzyl Adenine; NAA:Naphthaleneacetic Acid; 2, 4-D:2, 4Dichlorophenoxylacetic acid

Table 2. The effects of various concentrations of NAA, 2, 4-D alone or each separately combined with kinetin on callus/shoot induction from cotyledon, stem and nodal explants of E. cyclocarpum

\begin{tabular}{|c|c|c|c|c|c|c|}
\hline \multirow[t]{2}{*}{$\mathrm{S} / \mathrm{N}$} & \multicolumn{3}{|c|}{$\begin{array}{c}\text { MS medium + PGR concentration } \\
(\mu \mathrm{M})\end{array}$} & \multirow{2}{*}{$\begin{array}{l}\text { \% response of } \\
\text { cotyledon explant } \\
(\text { mean } \pm \text { S.E })\end{array}$} & \multirow{2}{*}{$\begin{array}{c}\text { \% response of } \\
\text { nodal explant } \\
(\text { mean } \pm \text { S.E })\end{array}$} & \multirow{2}{*}{$\begin{array}{l}\text { \% response of } \\
\text { stem explant } \\
(\text { mean } \pm \text { S.E })\end{array}$} \\
\hline & KIN & NAA & $2,4-\mathrm{D}$ & & & \\
\hline 1. & - & - & - & $0.00 \pm 0.00^{\mathrm{a}}$ & $0.00 \pm 0.00^{\mathrm{a}}$ & $0.00 \pm 0.00^{\mathrm{a}}$ \\
\hline 2. & - & - & 2.25 & $34.59 \pm 3.01^{\mathrm{cd}}$ & $48.47 \pm 1.10^{\mathrm{cd}}$ & $43.80 \pm 2.50^{\text {defg }}$ \\
\hline 3. & - & - & 4.50 & $34.22 \pm 3.62^{\text {cde }}$ & $43.40 \pm 1.47^{\mathrm{bc}}$ & $48.10 \pm 4.31^{\mathrm{eg}}$ \\
\hline 4. & - & - & 9.00 & $0.00 \pm 0.00^{\mathrm{a}}$ & $39.73 \pm 1.88^{b}$ & $41.60 \pm 2.31^{\text {cdef }}$ \\
\hline 5. & - & 2.70 & - & $48.40 \pm 1.24^{\mathrm{f}}$ & $55.37 \pm 43^{\mathrm{de}}$ & $45.8 \pm 3.06^{\mathrm{efg}}$ \\
\hline 6. & - & 5.40 & - & $41.03 \pm 2.48^{\mathrm{de}}$ & $51.43 \pm 2.38^{\mathrm{d}}$ & $50.37 \pm 6.07^{\text {gh }}$ \\
\hline 7. & - & 10.80 & - & $0.00 \pm 0.00^{a}$ & $48.13 \pm 1.40^{\text {cd }}$ & $45.67 \pm 2.83^{\text {efg }}$ \\
\hline 8. & 2.35 & - & - & $0.00 \pm 0.00^{\mathrm{a}}$ & $70.90 \pm 0.86^{\text {ghijk }}$ & $0.00 \pm 0.00^{\mathrm{a}}$ \\
\hline 9. & 2.35 & - & 2.25 & $44.50 \pm 4.75^{\mathrm{ef}}$ & $73.73 \pm 1.45^{\mathrm{jkl}}$ & $41.47 \pm 1.91^{\text {cdef }}$ \\
\hline 10. & 2.35 & - & 4.50 & $41.23 \pm 1.37^{\mathrm{de}}$ & $79.2 \pm 2.77^{1}$ & $50.27 \pm 1.21^{\mathrm{gh}}$ \\
\hline 11. & 2.35 & - & 9.00 & $0.00 \pm 0.00^{\mathrm{a}}$ & $67.20 \pm 3.24^{\text {fghij }}$ & $35.57 \pm 2.80^{\mathrm{bcd}}$ \\
\hline 12. & 2.35 & 2.70 & - & $49.43 \pm 2.048^{f}$ & $79.87 \pm 2.43^{1}$ & $42.83 \pm 2.70^{\text {cdefg }}$ \\
\hline 13. & 2.35 & 5.40 & - & $48.67 \pm 4.50^{f}$ & $78.13 \pm 1.24^{\mathrm{jkl}}$ & $43.97 \pm 2.53^{\text {defg }}$ \\
\hline 14. & 2.35 & 10.80 & - & $24.90 \pm 2.25^{b}$ & $71.00 \pm 3.27^{\text {ghijk }}$ & $47.73 \pm 3.36^{\text {fg }}$ \\
\hline 15. & 4.70 & - & - & $0.00 \pm 0.00^{\mathrm{a}}$ & $72.23 \pm 2.01^{\text {hijkl }}$ & $0.00 \pm 0.00^{\mathrm{a}}$ \\
\hline 16. & 4.70 & - & 2.25 & $35.70 \pm 2.76^{\mathrm{cd}}$ & $74.87 \pm 2.71^{\mathrm{jkl}}$ & $61.73 \pm 1.84^{\mathrm{ij}}$ \\
\hline 17. & 4.70 & - & 4.50 & $35.47 \pm 2.71^{\mathrm{cd}}$ & $78.20 \pm 3.93^{\mathrm{jkl}}$ & $75.53 \pm 2.88^{1}$ \\
\hline 18. & 4.70 & - & 9.00 & $0.00 \pm 0.00^{\mathrm{a}}$ & $64.60 \pm 3.18^{\text {fgh }}$ & $71.67 \pm 2.02^{\mathrm{kl}}$ \\
\hline 19. & 4.70 & 2.70 & - & $51.57 \pm 1.88^{f}$ & $73.431 \pm 1.35^{\mathrm{ijk}}$ & $62.90 \pm 2.80^{\mathrm{ij}}$ \\
\hline 20. & 4.70 & 5.40 & - & $47.50 \pm 4.62^{\mathrm{ef}}$ & $74.60 \pm 2.81^{\mathrm{kl}}$ & $67.567 \pm 2.39^{\mathrm{jk}}$ \\
\hline 21. & 4.70 & 10.80 & - & $0.00 \pm 0.00^{\mathrm{a}}$ & $69.70 \pm 2.98^{\text {ghij }}$ & $56.10 \pm 4.80^{\mathrm{hi}}$ \\
\hline 22. & 9.40 & - & - & $0.00 \pm 0.00^{\mathrm{a}}$ & $62.77 \pm 2.98^{\mathrm{fg}}$ & $0.00 \pm 0.00^{\mathrm{a}}$ \\
\hline 23. & 9.40 & - & 2.25 & $29.63 \pm 2.14^{\text {bc }}$ & $68.40 \pm 2.11^{\text {ghij }}$ & $40.93 \pm 0.88^{\text {cdef }}$ \\
\hline 24. & 9.40 & - & 4.50 & $33.73 \pm 2.64^{\mathrm{c}}$ & $68.03 \pm 1.87^{\text {ghij }}$ & $41.30 \pm 2.45^{\text {cdef }}$ \\
\hline 25. & 9.40 & - & 9.00 & $0.00 \pm 0.00^{\mathrm{a}}$ & $59.80 \pm 2.06^{\mathrm{ef}}$ & $29.10 \pm 0.81^{b}$ \\
\hline 26. & 9.40 & 2.70 & - & $35.03 \pm 3.43^{\mathrm{cd}}$ & $68.83 \pm 2.39^{\text {ghij }}$ & $39.70 \pm 5.11^{\text {cdef }}$ \\
\hline 27. & 9.40 & 5.40 & - & $31.73 \pm 2.21^{\mathrm{c}}$ & $65.40 \pm 2.84^{\text {fghi }}$ & $34.73 \pm 2.96^{b c}$ \\
\hline 28. & 9.40 & 10.80 & - & $0.00 \pm 0.00^{\mathrm{a}}$ & $64.57 \pm 2.86^{\mathrm{fgh}}$ & $38.83 \pm 1.71^{\text {cde }}$ \\
\hline
\end{tabular}

PGR: Plant growth regulators; KIN:Kinetin; NAA:Naphthaleneacetic Acid; 2, 4-D:2, 4-Dichlorophenoxylacetic acid

Table 3. The effects of various concentration of NAA, 2, 4-D alone or each separately combined with BA on caulogenesis from stem, cotyledon and nodal explants of E. cyclocarpum

\begin{tabular}{|c|c|c|c|c|c|c|c|c|}
\hline \multirow[t]{2}{*}{$\mathrm{S} / \mathrm{N}$} & \multicolumn{3}{|c|}{$\begin{array}{l}\text { MS medium + PGR } \\
\text { Concentration }(\mu \mathrm{M})\end{array}$} & \multirow{2}{*}{$\begin{array}{c}\text { Degree of } \\
\text { cotyledon callus } \\
\text { formation }\end{array}$} & \multirow{2}{*}{$\begin{array}{c}\text { No. of shoot } \\
\text { per cotyledon } \\
\text { explants }\end{array}$} & \multirow{2}{*}{$\begin{array}{c}\text { Degree of } \\
\text { nodal callus } \\
\text { formation }\end{array}$} & \multirow{2}{*}{$\begin{array}{c}\text { No. of shoot } \\
\text { per nodal } \\
\text { explants }\end{array}$} & \multirow{2}{*}{$\begin{array}{l}\text { Degree of } \\
\text { stem callus } \\
\text { formation }\end{array}$} \\
\hline & $\mathrm{BA}$ & NAA & $2,4-\mathrm{D}$ & & & & & \\
\hline 1. & - & - & - & No callus & & No callus & & No callus \\
\hline 2. & - & - & 2.25 & + & & + & & + \\
\hline 3. & - & - & 4.5 & + & & + & & ++ \\
\hline 4. & - & - & 9.0 & No callus & & + & & ++ \\
\hline 5. & - & 2.7 & - & + & & + & & + \\
\hline 6. & - & 5.4 & - & + & & + & & + \\
\hline 7. & - & 10.8 & - & No callus & & + & & + \\
\hline 8. & 2.2 & - & - & No callus & & $++S$ & $1.50 \pm 0.40^{\mathrm{abc}}$ & No callus \\
\hline 9. & 2.2 & - & 2.25 & $+S$ & $0.80 \pm 0.12^{\mathrm{a}}$ & $++S$ & $1.70 \pm 0.30^{\mathrm{bcd}}$ & ++ \\
\hline
\end{tabular}


Akinropo MS et al. (2020). Not Sci Biol 12(1):74-89.

80

\begin{tabular}{|c|c|c|c|c|c|c|c|c|}
\hline 10. & 2.2 & - & 4.5 & $+S$ & $1.40 \pm 0.17^{\mathrm{a}}$ & ++ & & ++ \\
\hline 11. & 2.2 & - & 9.0 & + & & ++ & & + \\
\hline 12. & 2.2 & 2.7 & - & $+S$ & $2.1 \pm 0.11^{\mathrm{d}}$ & $+++S$ & $1.80 \pm 0.50^{\text {cde }}$ & ++ \\
\hline 13. & 2.2 & 5.4 & - & + & & $++S$ & $2.70 \pm 0.20^{\text {efgh }}$ & ++ \\
\hline 14. & 2.2 & 10.8 & - & + & & +++ & & ++ \\
\hline 15. & 4.4 & - & - & No callus & & $++S$ & $2.80 \pm 0.40^{\text {efgh }}$ & No callus \\
\hline 16. & 4.4 & - & 2.25 & $+S$ & $1.40 \pm 0.20^{\text {bc }}$ & $++S$ & $2.50 \pm 0.50 \mathrm{~d}^{\text {efg }}$ & ++ \\
\hline 17. & 4.4 & - & 4.5 & + & & $++S$ & $2.00 \pm 0.30^{\text {def }}$ & + \\
\hline 18. & 4.4 & - & 9.0 & + & & ++ & & No callus \\
\hline 19. & 4.4 & 2.7 & - & $+S$ & $1.30 \pm 0.18^{\text {ab }}$ & $++S$ & $3.00 \pm 0.50^{\text {fgh }}$ & ++ \\
\hline 20. & 4.4 & 5.4 & - & + & & $++S$ & $2.70 \pm 0.40^{\text {efgh }}$ & +++ \\
\hline 21. & 4.4 & 10.8 & - & + & & ++ & $2.10 \pm 0.30^{\text {def }}$ & ++ \\
\hline 22. & 8.8 & - & - & No callus & & $++S$ & $3.00 \pm 0.60^{\text {fgh }}$ & No callus \\
\hline 23. & 8.8 & - & 2.25 & + & $1.60 \pm 0.23^{\text {bcd }}$ & $++S$ & $3.10 \pm 0.50^{\text {fgh }}$ & + \\
\hline 24. & 8.8 & - & 4.5 & + & & $+S$ & $2.60 \pm 0.40^{\text {efgh }}$ & + \\
\hline 25. & 8.8 & - & 9.0 & No callus & & $+S$ & $1.90 \pm 0.30^{\text {cde }}$ & No callus \\
\hline 26. & 8.8 & 2.7 & - & + & $1.90 \pm 0.17^{\text {cd }}$ & $++S$ & $3.98 \pm 0.50^{\text {fghi }}$ & + \\
\hline 27. & 8.8 & 5.4 & - & ++ & & $++S$ & $2.70 \pm 0.50^{\text {efgh }}$ & + \\
\hline 28. & 8.8 & 10.8 & - & + & & $+++S$ & $1.80 \pm 0.40^{\text {cde }}$ & + \\
\hline
\end{tabular}

+ Slight callus formation; ++Moderate callus formation; +++ Massive callus formation

PGR: Plant growth regulators; BA: Benzyl adenine; NAA: Naphthaleneacetic Acid; 2, 4-D: 2, 4-

Dichlorophenoxylacetic acid; ${ }^{* *}$ S: Shoot initiation

Table 4. The effects of various concentrations of NAA, 2, 4-D alone or each separately combined with kinetin on caulogenesis from stem, cotyledon and nodal explants of E. cyclocarpum

\begin{tabular}{|c|c|c|c|c|c|c|c|c|}
\hline \multirow[t]{2}{*}{$\mathrm{S} / \mathrm{N}$} & \multicolumn{3}{|c|}{$\begin{array}{l}\text { MS medium + PGR } \\
\text { Concentration }(\mu \mathrm{M})\end{array}$} & \multirow{2}{*}{$\begin{array}{c}\text { Degree of } \\
\text { cotyledon callus } \\
\text { formation }\end{array}$} & \multirow{2}{*}{$\begin{array}{l}\text { No. of shoot } \\
\text { per cotyledon } \\
\text { explants }\end{array}$} & \multirow{2}{*}{$\begin{array}{c}\text { Degree of } \\
\text { nodal callus } \\
\text { formation }\end{array}$} & \multirow{2}{*}{$\begin{array}{l}\text { No. of shoot } \\
\text { per nodal } \\
\text { explants }\end{array}$} & \multirow{2}{*}{$\begin{array}{l}\text { Degree of } \\
\text { stem callus } \\
\text { formation }\end{array}$} \\
\hline & KIN & NAA & $2,4-D$ & & & & & \\
\hline 1. & - & - & - & No callus & & No callus & & No callus \\
\hline 2. & - & - & 2.25 & + & & ++ & & + \\
\hline 3. & - & - & 4.50 & + & & ++ & & ++ \\
\hline 4. & - & - & 9.00 & No callus & & + & & ++ \\
\hline 5. & - & 2.70 & - & + & & ++ & & + \\
\hline 6. & - & 5.40 & - & + & & ++ & & + \\
\hline 7. & - & 10.80 & - & No callus & & + & & ++ \\
\hline 8. & 2.35 & - & - & No callus & & $++S$ & $1.40 \pm 0.40^{\mathrm{abc}}$ & No callus \\
\hline 9. & 2.35 & - & 2.25 & + & & $++S$ & $1.30 \pm 0.30^{\mathrm{ab}}$ & + \\
\hline 10. & 2.35 & - & 4.50 & ++ & & ++ & & + \\
\hline 11. & 2.35 & - & 9.00 & No callus & & + & & \\
\hline 12. & 2.35 & 2.70 & - & $+S$ & $1.4 \pm 0.05^{\mathrm{b}}$ & $+S$ & $2.30 \pm 0.11^{\text {defgh }}$ & ++ \\
\hline 13. & 2.35 & 5.40 & - & $+S$ & $0.8 \pm 0.11^{a}$ & $+S$ & $2.40 \pm 0.50^{\text {efgh }}$ & ++ \\
\hline 14. & 2.35 & 10.80 & - & + & & +++ & & ++ \\
\hline 15. & 4.70 & - & - & No callus & & $+S$ & $2.10 \pm 0.17^{\text {cdfg }}$ & No callus \\
\hline 16. & 4.70 & - & 2.25 & $++S$ & $0.17 \pm 0.11^{\mathrm{ab}}$ & $++S$ & $2.30 \pm 0.11^{\text {defg }}$ & ++ \\
\hline 17. & 4.70 & - & 4.50 & + & & $++S$ & $2.00 \pm 0.18^{\text {bcdef }}$ & +++ \\
\hline 18. & 4.70 & - & 9.00 & No callus & & + & & ++ \\
\hline 19. & 4.70 & 2.70 & - & $+S$ & $1.5 \pm 0.12^{b}$ & $++S$ & $3.50 \pm 0.28^{i j}$ & ++ \\
\hline 20. & 4.70 & 5.40 & - & + & & $++S$ & $3.0 \pm 0.23^{\text {hi }}$ & +++ \\
\hline 21. & 4.70 & 10.80 & - & No callus & & + & & + \\
\hline
\end{tabular}


Akinropo MS et al. (2020). Not Sci Biol 12(1):74-89.

\begin{tabular}{|c|c|c|c|c|c|c|c|c|}
\hline 22. & 9.40 & - & - & No callus & & $+S$ & $3.50 \pm 0.40^{\mathrm{ij}}$ & No callus \\
\hline 23. & 9.40 & - & 2.25 & + & & $+S$ & $3.70 \pm 0.29^{\mathrm{j}}$ & + \\
\hline 24. & 9.40 & - & 4.50 & $+S$ & $1.20 \pm 0.23^{\mathrm{ab}}$ & $+S$ & $2.50 \pm 0.40^{\text {fgh }}$ & + \\
\hline 25. & 9.40 & - & 9.00 & No callus & & $+S$ & $2.20 \pm 0.30^{\text {defg }}$ & + \\
\hline 26. & 9.40 & 2.70 & - & + & & $+S$ & $3.30 \pm 0.50^{\text {ghi }}$ & + \\
\hline 27. & 9.40 & 5.40 & - & + & & $+S$ & $3.60 \pm 0.50^{\mathrm{ij}}$ & + \\
\hline 28. & 9.40 & 10.80 & - & No callus & & $+S$ & $0.28 \pm 0.35^{\text {gh }}$ & + \\
\hline
\end{tabular}

+ Slight callus formation; ++ Moderate callus formation; +++ Massive callus formation

PGR: Plant growth regulators; KIN: Kinetin; NAA: Naphthaleneacetic Acid; 2, 4-D: 2, 4-Dichlorophenoxylacetic acid; ${ }^{* *}$ : Shoot initiation

Table 5. The effects of various concentrations of NAA, 2, 4-D alone or each separately combined with BA on morphology of callus from stem, cotyledon and nodal explants of E. cyclocarpum

\begin{tabular}{|c|c|c|c|c|c|c|}
\hline \multirow[t]{2}{*}{$\mathrm{S} / \mathrm{N}$} & \multicolumn{3}{|c|}{$\begin{array}{l}\text { MS medium + PGR } \\
\text { concentration }(\mu \mathrm{M})\end{array}$} & \multirow{2}{*}{$\begin{array}{l}\text { Morphology of } \\
\text { cotyledon callus }\end{array}$} & \multirow{2}{*}{$\begin{array}{l}\text { Morphology of } \\
\text { nodal callus }\end{array}$} & \multirow{2}{*}{$\begin{array}{l}\text { Morphology of } \\
\text { stem callus }\end{array}$} \\
\hline & $\mathrm{BA}$ & NAA & $2,4-\mathrm{D}$ & & & \\
\hline 1. & - & - & - & - & - & - \\
\hline 2. & - & - & 2.25 & Light brown and hard & White and friable & Light brown and rather hard \\
\hline 3. & - & - & 4.5 & Light brown and hard & White and friable & Light brown and rather hard \\
\hline 4. & - & - & 9.0 & - & White and friable & Light brown and rather hard \\
\hline 5. & - & 2.7 & - & Light brown and hard & White and friable & Creamy/ semi hard \\
\hline 6. & - & 5.4 & - & Light brown and hard & White and friable & Creamy/ semi hard \\
\hline 7. & - & 10.8 & - & - & White and friable & Creamy/ semi hard \\
\hline 8. & 2.2 & - & - & - & White and friable & \\
\hline 9. & 2.2 & - & 2.25 & Brown and granular & White and friable & Light brown and semi hard \\
\hline 10. & 2.2 & - & 4.5 & Light brown and hard & White and friable & Light brown and semi hard \\
\hline 11. & 2.2 & - & 9.0 & Brown and hard & White and friable & Light brown and semi hard \\
\hline 12. & 2.2 & 2.7 & - & Brown and hard & White and friable & Light brown and Friable \\
\hline 13. & 2.2 & 5.4 & - & light and loose yellow & White and friable & Light brown and Friable \\
\hline 14. & 2.2 & 10.8 & - & light and loose yellow & White and friable & Light brown and Friable \\
\hline 15. & 4.4 & - & - & - & White and friable & \\
\hline 16. & 4.4 & - & 2.25 & Light brown and hard & White and friable & Light brown and semi hard \\
\hline 17. & 4.4 & - & 4.5 & Light brown and hard & White and friable & Light brown and semi hard \\
\hline 18. & 4.4 & - & 9.0 & Light brown and granular & White and friable & \\
\hline 19. & 4.4 & 2.7 & - & Light and friable yellow & White and friable & Light brown and Friable \\
\hline 20. & 4.4 & 5.4 & - & Light yellow and friable & White and friable & Light brown and Friable \\
\hline 21. & 4.4 & 10.8 & - & & White and friable & Light brown and Friable \\
\hline 22. & 8.8 & - & - & & White and friable & \\
\hline 23. & 8.8 & - & 2.25 & Light brown and semi-hard & White and friable & Light brown and semi hard \\
\hline 24. & 8.8 & - & 4.5 & \begin{tabular}{l|l} 
Hard & \\
\end{tabular} & White and friable & Light brown and semi hard \\
\hline 25. & 8.8 & - & 9.0 & & White and friable & \\
\hline 26. & 8.8 & 2.7 & - & Light yellow and rath. hard & White and friable & Light brown and semi hard \\
\hline 27. & 8.8 & 5.4 & - & Light yellow and hard & White and friable & \\
\hline 28. & 8.8 & 10.8 & - & Light yellow and hard & White and friable & Light brown and semi hard \\
\hline
\end{tabular}

PGR: Plant growth regulators; BA: Benzyl Adenine; NAA: Naphthaleneacetic Acid; 2, 4-D: 2, 4Dichlorophenoxylacetic acid

The stem explants of E. cyclocarpum explanted on MS medium alone grew in size, expanded longitudinally and laterally at first but later the cut edges began to turn brown and the explants died ultimately. The stem explants explanted on MS medium supplemented with either BA or kinetin alone did not show callogenesis. With MS medium containing the individual auxin, callus initiation appeared after 3 weeks 
82

followed by a very slow proliferation of creamy/ off white hard callus (Figure 3b). The NAA/ BA or 2,4-D/ BA combinations brought about callus initiation in the stem explants within 2 weeks to produce off white friable or semi-hard (Tables 5 and 6). The largest callus size was produced in stem explants cultured on MS medium containing 5.4 $\mu \mathrm{M} \mathrm{NAA}+4.4 \mu \mathrm{M}$ BA (Figure $4 \mathrm{a}$ ), and $82.2 \pm 2.63 \%$ response was obtained (Table 1). The combination of NAA/ kinetin and 2,4-D/ kinetin induced callus from the stem explants of $E$. cyclocarpum within 2 weeks, the calli were generally light brown and semi-hard. Massive callus induction was observed with stem explants of E. cyclocarpum cultured on MS medium supported with 4.5 $\mu \mathrm{M} 2,4-\mathrm{D}+4.7$ $\mu \mathrm{M}$ kinetin with the highest frequency of $75.53 \pm 2.88 \%$ (Table 2 ).

Nodal explants of E. cyclocarpum cultured on MS medium alone enlarged in size without either production of callus or axillary bud release. When the explants were grown on MS medium to which auxins alone were added, the only callus formed and with auxin/cytokinin combinations, both callus and shoot buds were observed within 2 weeks of culture. Calli formed at the basal cut ends of the explants in all the cases were cream-coloured or white and friable.

The highest frequency of callus formation $(81.57 \pm 1.92)$ was induced from nodal explants cultured on MS medium supplemented with $2.7 \mu \mathrm{M}$ NAA $+2.2 \mu \mathrm{M}$ BA (Table 1) and the maximum shoot/explants induced (4.0) was obtained from nodal explant cultured on MS medium supplemented with $2.7 \mu \mathrm{M}$ NAA + $8.8 \mu \mathrm{M}$ BA (Table 3). Massive callus formed from nodal explants with the highest frequency $(79.2 \pm 2.77 \%)$ when cultured on MS medium supplemented with $4.5 \mu \mathrm{M} 2,4-\mathrm{D}+2.35 \mu \mathrm{M}$ kinetin (Table 2). Callus and shoot buds induced by $4.5 \mu \mathrm{M}$ 2,4-D + $2.35 \mu \mathrm{M}$ Kinetin, while callus and short buds induced from nodal explants cultured on MS medium supported with 2.7 $\mu \mathrm{M}$ NAA + $2.2 \mu \mathrm{M}$ BA after 4 weeks (Figure $4 \mathrm{~b}$ and 5). On the subculture of shoot buds so induced from nodal explant-derived callus, they showed extended growth without root formation.

On the transfer of separated shoot buds to MS medium without hormones, less than $10 \%$ of them rooted after 6 weeks of culture. In MS medium containing $4.9 \mu \mathrm{M}$ IBA, short and thick roots formed in over $80 \%$ of the shoots within 4 weeks of culture. Figure 6 shows the acclimatized plantlets induced from nodal explant of E. cyclocarpum with thick root in a rooting medium of $4.9 \mu \mathrm{M}$ IBA.
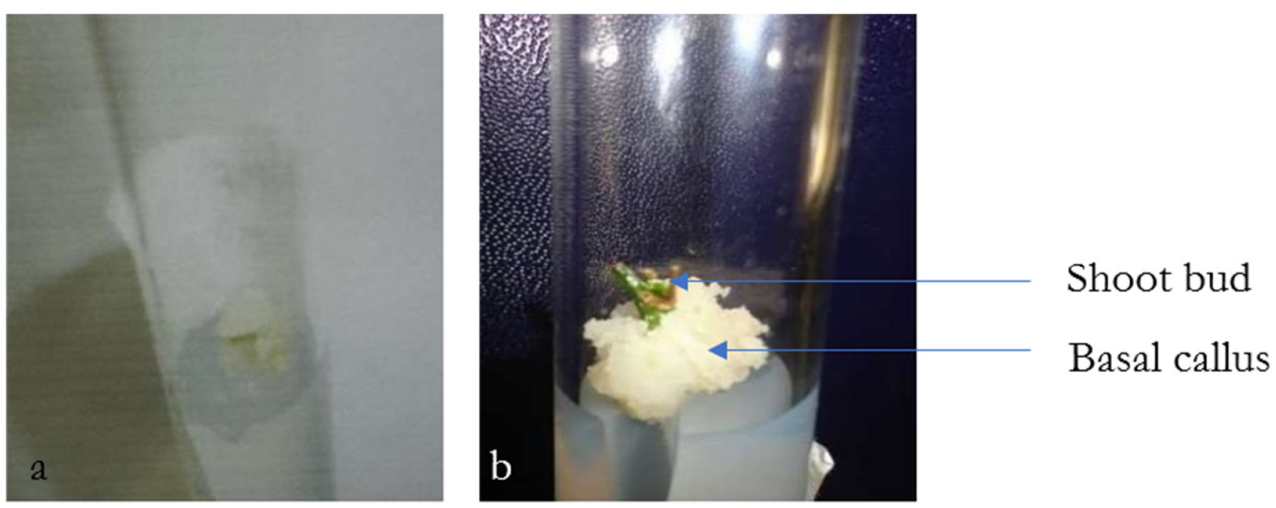

Figure 4. Callus and basal callus with shoot induced from stem and nodal explant of E. cyclocarpum after four weeks of culture respectively on MS Supplemented $5.4 \mu \mathrm{M}$ NAA $+4.4 \mu \mathrm{M}$ BA for the stem(a) and 4.5 $\mu \mathrm{M} 2,4-\mathrm{D}+2.35 \mu \mathrm{M}$ Kinetin for the node(b) 


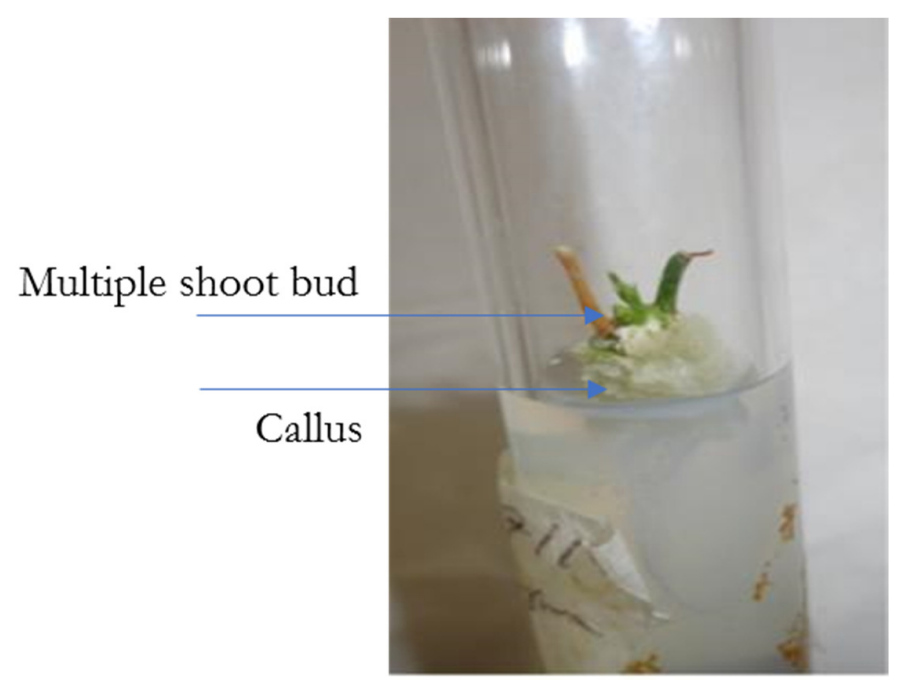

Figure 5. Basal callus with shoot buds obtained from nodal explant of E. cyclocarpum after four weeks of culture on ms supplemented with $2.7 \mu \mathrm{M}$ NAA $+2.2 \mu \mathrm{M}$ BA

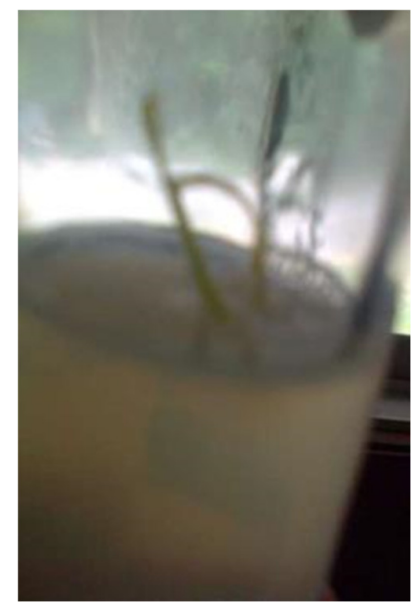

Figure 6: Acclimatized plantlets of E. cyclocarpum with thick roots

Table 6. The effects of various concentrations of NAA, 2, 4-D alone or each separately combined with kinetin on morphology of callus from stem, cotyledon and nodal explants of E. cyclocarpum

\begin{tabular}{|c|c|c|c|c|c|c|}
\hline \multirow[t]{2}{*}{$\mathrm{S} / \mathrm{N}$} & \multicolumn{3}{|c|}{$\begin{array}{l}\text { MS medium + PGR } \\
\text { concentration }(\mu \mathrm{M})\end{array}$} & \multirow{2}{*}{$\begin{array}{l}\text { Morphology of } \\
\text { cotyledon callus }\end{array}$} & \multirow{2}{*}{$\begin{array}{l}\text { Morphology of } \\
\text { nodal callus }\end{array}$} & \multirow{2}{*}{$\begin{array}{l}\text { Morphology of } \\
\text { stem callus }\end{array}$} \\
\hline & KIN & NAA & $2,4-\mathrm{D}$ & & & \\
\hline 1. & - & - & - & - & - & - \\
\hline 2. & - & - & 2.25 & Light brown and hard & White and friable & - \\
\hline 3. & - & - & 4.50 & Light brown and hard & White and friable & Light brown and rather hard \\
\hline 4. & - & - & 9.00 & - & White and friable & Light brown and rather hare \\
\hline 5. & - & 2.70 & - & $\begin{array}{l}\text { Light brown and } \\
\text { rather hard }\end{array}$ & White and friable & Creamy/semi hard \\
\hline 6. & - & 5.40 & - & $\begin{array}{l}\text { Light brown and } \\
\text { rather hard }\end{array}$ & White and friable & Creamy/semi hard \\
\hline 7. & - & 10.80 & - & Light brown and hard & White and friable & Creamy/semi hard \\
\hline 8. & 2.35 & - & - & - & Creamy and friable & - \\
\hline
\end{tabular}


Akinropo MS et al. (2020). Not Sci Biol 12(1):74-89.

84

\begin{tabular}{|c|c|c|c|c|c|c|}
\hline 9. & 2.35 & - & 2.25 & Light brown and hard & Creamy and friable & Light brown and semi hard \\
\hline 10. & 2.35 & - & 4.50 & Light brown and hard & Creamy and friable & Light brown and semi hard \\
\hline 11. & 2.35 & - & 9.00 & & Creamy and friable & Light brown and semi hard \\
\hline 12. & 2.35 & 2.70 & - & Light brown and hard & Creamy and friable & Light brown and semi hard \\
\hline 13. & 2.35 & 5.40 & - & Light yellow and hard & Creamy and friable & Light brown and semi hard \\
\hline 14. & 2.35 & 10.80 & - & Light yellow and hard & Creamy and friable & Light brown and semi hard \\
\hline 15. & 4.70 & - & - & - & Creamy and friable & - \\
\hline 16. & 4.70 & - & 2.25 & Deep brown and hard & Creamy and friable & Light brown and semi hard \\
\hline 17. & 4.70 & - & 4.50 & Light yellow and hard & Creamy and friable & Light brown and semi hard \\
\hline 18. & 4.70 & - & 9.00 & - & Creamy and friable & Light brown and semi hard \\
\hline 19. & 4.70 & 2.70 & - & Light brown and hard & Creamy and friable & Light brown and semi hard \\
\hline 20. & 4.70 & 5.40 & - & Light yellow and hard & Creamy and friable & Light brown and semi hard \\
\hline 21. & 4.70 & 10.80 & - & - & Creamy and friable & Light brown and semi hard \\
\hline 22. & 9.40 & - & - & - & Creamy and friable & - \\
\hline 23. & 9.40 & - & 2.25 & Deep brown and hard & Creamy and friable & Light brown and semi hard \\
\hline 24. & 9.40 & - & 4.50 & Light yellow and hard & Creamy and friable & Light brown and semi hard \\
\hline 25. & 9.40 & - & 9.00 & - & Creamy and friable & Light brown and semi hard \\
\hline 26. & 9.40 & 2.70 & - & Light brown and hard & Creamy and friable & Light brown and semi hard \\
\hline 27. & 9.40 & 5.40 & - & Light brown and hard & Creamy and friable & Light brown and semi hard \\
\hline 28. & 9.40 & 10.80 & & - & Creamy and friable & Light brown and semi hard \\
\hline
\end{tabular}

\section{Discussion}

The use of in vitro approaches to propagation, conservation and genetic improvement of forest trees has been of increased interest since the last three decades (Chalupa, 1981; Tomar and Gupta, 1988; Xia and Hong, 2001; Chalupa, 2002; Anis et al., 2005; Faisal, 2007; Renukdas et al., 2010 and Sajeevan et al., 2013). Two methods of plant regeneration widely used in rapid and large scale micropropagation or plant transformation studies are organogenesis or embryogenesis. The success of these techniques requires good callus quality and quantity (Lin et al., 2010).

The present studies showed that the stem, cotyledon, and nodal explants, but not leaf explants of $E$. cyclocarpum species were callogenic. The initiation and proliferation of callus were promoted by using NAA, 2,4-D alone or separately combined with Kinetin or BA to different extents in different explants. It was generally observed that the percentage of explants response in terms of callus induction was greater with auxin combination with BA than with Kinetin in the explants studied. The auxins, NAA and 2,4-D are commonly used with BA for callus induction in plant systems (Dhar and Joshi, 2005; Abbasin et al., 2010; Isikalam et al., 2010; Ntui et al., 2012). Other research groups also induced callus, a consequence of wound reaction (Khal, 1983), in vitro without the use of plant growth regulators of several plant species (Handro and Floh, 2001; Martin, 2002).

Cotyledon explants of E. cyclocarpum were found to produce callus together with shoot buds when cultured on MS medium containing NAA combined with BA or Kinetin. The frequency of shoot induction appeared favoured by high cytokinin relative to auxin. A combination of $2.2 \mu \mathrm{MBA}+2.7 \mu \mathrm{M}$ NAA induced the best shoot production from the cotyledon explants of $E$. cyclocarpum (2.1 shoots/explant). The influencing 
effects of auxin and cytokinin combination on organogenic differentiation have been well documented in several plant systems. Rahman et al. (2010) found that adventitious shoots were induced from leaf-derived callus of Lagerstroemia speciosa grown on MS medium that was supplemented with $5 \mu \mathrm{MBA}, 3 \mu \mathrm{M}$ NAA, $10 \%$ coconut milk and $568 \mu \mathrm{M}$ ascorbic acid. Similarly, cotyledon derived calli induced by $0.5 \mu \mathrm{M}$ NAA $+0.5 \mu \mathrm{M}$ BA produced high-efficiency shoot regeneration (4.2 shoots/explant) when subcultured on MS medium supplemented with $5 \mu \mathrm{M}$ BA (Agrawal and Sadar, 2007). Salvi et al. (2001) who used various Neem explants including cotyledon, produced multiple shoots on MS medium containing $8.88 \mu \mathrm{M}$ BA and $0.57 \mu \mathrm{M}$ NAA. By addition of $3 \mathrm{mg} / \mathrm{L}$ Hymexazol to a modified MS medium containing $2.22 \mu \mathrm{M}$ BA and $0.05 \mu \mathrm{M}$ NAA, Yin $e t$ al. (2001) increased adventitious shoot development from cotyledon explants of Albizia julibrissin.

The leaf explants of E. cyclocarpum formed no callus when cultured on either MS medium alone or supplemented with various concentrations of either BA or NAA alone and in their combinations. The leaf explants, however, were found to have lost chlorophyll turning light green the end. This is contrary to wound reaction inducing mitosis in the cells from the cut surfaces and culminating in callus formation (Pérez-Francés et al., 1995). The loss of response of the explants may suggest that the endogenous level of auxins/cytokinin or the exogenously applied growth regulators were insufficient to induce callus. It is also known that different tissues can respond in different ways during in vitro culture process (Jimenez, 2001; Banerjee et al., 2011), and the requirements for plant growth regulators appear to be tissue-specific (Venkatachalam et al., 1999; Banerjee et al., 2011). Vidoz et al. (2012) also reported that the leaf explants of Lotononis bainesii did not respond on MS media to the absence of plant growth regulators. Conversely, leaf explants have been reported by several authors as the best for callus induction and shoot initiation. Jiancan et al. (2011) obtained 95\% callus induction from leaf explants of Zizyphus jujuba in MS supplemented with $0.5 \mathrm{mg} / \mathrm{L}$ NAA.

In the absence of growth regulators in the culture medium, E. cyclocarpum stem explants neither formed callus nor shoot buds. The stem explants inoculated either on MS medium alone or supplemented with BA alone did not show callogenesis or caulogenesis but they first increased in size and gradually turned brown later. Cultures of stem explants on MS medium supplemented with the different concentrations of auxin and combined with BA started callus initiation after 2 weeks and proceeded with high proliferation.

Nodal explants exhibited the greatest tendencies to form callus and shoots under the influence of plant growth regulators compared to stem, hypocotyl, leaf and cotyledon explants of the plant species investigated. An average of 3.98 shoot / explant was generated from the nodal explant-induced callus of E. cyclocarpum by $2.7 \mu \mathrm{M}$ NAA combined with $8.8 \mu \mathrm{M}$ BA.

The nodal explants of several tree seedlings have been known to produce both callus and shoot buds in vitro under the influence of some plant growth regulators. Rahman et al. (1993) reported that NAA or 2,4-D separately combined with BA induced both callus and shoots within 3 weeks of culture of nodal explants of Caesalpinea Pulcherima. Sugla et al. (2007) induced multiple shoots in vitro from nodal explants through forced axillary branching in Pongamia pinnata using 7.5 $\mu \mathrm{M}$ BA while more recently, Sajeevan et al. (2012) reported inducing multiple shoots from nodal explants of Morus alba L. variety VI cultured on MS medium supplemented with $1.0 \mathrm{mg} / \mathrm{L}$ BAP, $0.1 \mathrm{mg} / \mathrm{L}$ TDZ and $0.25 \mathrm{mg} / \mathrm{L}$ NAA. Maximum shoot induction was obtained from the nodal cutting of E. cyclocarpum seedlings cultured on MS medium supplemented with a combination of $10.7 \mu \mathrm{M}$ NAA and $2.2 \mu \mathrm{M}$ BA (Rodriquez-Sahagun et al., 2007). Multiple shoots were also obtained from nodal explants of 18-day-old in vitro seedlings of Pterocarpus marsupium Roxb. culture on MS medium containing $4 \mu \mathrm{M} \mathrm{BA}, 0.5 \mu \mathrm{M}$ NAA and $20 \mu \mathrm{M}$ adenine sulphate (Husain et al., 2008). Shoot proliferation from nodal explants of Melaleuca alternifolia (Tee Tee) cultured in liquid or on agar-based MS medium containing $1.11 \mu \mathrm{M} \mathrm{BA}$ or $0.55 \mu \mathrm{M}$ BA had also been reported in the literature (Yohana et al., 2010).

Root induction was also achieved in the rooting medium (MS + 4.9 $\mu \mathrm{M} \mathrm{IBA})$. Stout short single roots were induced from the cotyledon and nodal explant-derived shoots of E. cyclocarpum. It appears that different species have a different critical concentration of hormones below which root initiation will occur and above 
which there will be inhibition. Furthermore, organogenic differentiation of callus leading to production of shoots and roots are dependent on several factors aside from hormonal factors and these include level of salt (e.g. $\mathrm{PO}_{4}^{3-}$ ), quality of light, and temperature, in addition to physiological state, size of explant, and orientation of the medium (Razan, 2003). Chevre (1985) opined that rooting is often more difficult with the ligneous plants than with the herbaceous plants. More recently, similar observations were reported by Lin et al. (2010) stating that in general, establishing an efficient tissue culture technique was difficult in woody plants compared to herbaceous plants. This in part is related to the phase change from juvenility to maturation that most woody plants undergo (Trevor et al., 1990). The development of basal callus is one of the main physiological disorders that affect rooting competence of micro shoots, a situation which is more severe in woody species (Bairu and Kane, 2011). These authors explained that basal callus constitutes a sink trapping essential growth constituent and consequently affecting many physiological processes of the shoot.

\section{Conclusions}

The optimal concentration of NAA/BA that can induce stem callus in a potential source for plant regeneration (either by organogenesis or embryogenesis) and production of secondary metabolites were determined for E. cyclocarpum. Also, the optimal concentration of NAA/BA for shoot induction and plantlets formation of the plant species from cotyledon and nodal explants were also determined. Thus, it can be concluded by means of in vitro culture of the cotyledon and nodal explants of E. cyclocarpum, true clone plantlets can be produced. This plantlet can be employing for reforestation and/or forest restoration programs.

\section{Acknowledgements}

This research received no specific grant from any funding agency in the public, commercial, or private sectors. The authors are grateful to Emanuel Uwadone for his assistance in statistical analysis and all the anonymous reviewers.

\section{Conflict of Interests}

The authors declare that there are no conflicts of interest related to this article.

\section{References}

Abbasin Z, Zamani S, Movahedi S, Khaksar G, Tabatabael (2010). In vitro micropropagation of yew (Taxus baccata) and propagation of plantlets. Biotechnology 9:48-54.

Agrawal V, Sardar PR (2007). In vitro propagation of Cassia angustifolia through leaflet and cotyledon-derived calli. Biologia plantarum 50(1):118-122.

Anis M, Husain MK, Shahzad A (2005). In vitro plantlet regeneration of Pterocarpus marsupium Roxb., an endangered leguminous tree. Current Science 88:861- 863.

Araceli RS, Osvaldo ACH, Gustavo JAH (2007). In vitro propagation of Enterolobium cyclocarpum (Guanacaste) from nodal explants of axenic seedlings e-Gnosis. Vol. 5, Universidad de Guadalajara, Guadalajara, Mexico.

Bairu MW, Kane ME (2011). Physiological and developmental problems encountered by in vitro cultured plants. Plant Growth Regulation 63:101-103.

Banerjee M, Gantait S, Pramanik BR (2011). A two-step method for accelerated mass propagation of Dendrocalamus asper and their evaluation in field. Physiology and Molecular Biology of Plants 17(4):387-393.

Barwick M (2004). Tropical and subtropical trees - a worldwide encyclopedic guide. ISBN 0-500-51181-0P. 
Burkil HM (2004). The useful plants of west tropical Africa. Royal Botanic Gardens, Kew.

Carranza-Montaño MA, Sánchez-Velásquez LR, Pineda-López MR, Cuevas-Guzmán R (2003). Forrage quality and potential of species from the Sierra de Manantlán (México) tropical dry forest. Agrociencia 37(2):203-210.

Chalupa V (1981) Clonal Propagation of broad-leaved forest trees in vitro. Communications Institute Forestry Czechoslovakia 12:255-271.

Chalupa V (2002) In vitro propagation of mature trees of Sorbus aucuparia L. and field performance of micropropagated trees. Journal of forest science 48(12):529-535.

Chen Y, Cao FL, Li SX, Dao DW, Xu CP (2010). Establishment of highly efficient regeneration system with different explants of Sapium sabiferum in vitro. Acta Botanica Boreali-Occidentalia Sinica 30(12):2542-2549 (in Chinese).

Chevre, AM (1985). Research on in-vitro vegetative propagation in chestnut. Doctoral Thesis. University of Bordeaux II, pp 100.

de Oliveira Y, Pinto F, da Silwa ALL, Guedas I, Biasi LA, Quoirin M (2010). An efficient protocol for micropropagation of Melaleuca alternifolia Cheel. In Vitro Cell Developmental Biology - Plant 46:192-200.

Dhar U, Joshi M (2005). Efficient plant regeneration protocol through callus for Saussurea obvalata (Asteraceae): effect of explant type, age and plant growth regulators. Plant Cell Reports 24:195-200.

Eleanya K (2014). Promoting forests and forest products development. Production Agriculture and Technology 10(2):78-90.

Ezenwa I (1999). Preliminary evaluation of the suitability of Enterolobium cyclocarpum for use in intensive feed garden in Southwestern Nigeria. Agroforestry System 44(1):13-19.

Faisal M, Ahmad N, Anis M (2007). An efficient micropropagation system for Tylophora indica: an endangered medicinally important plant. Plant Biotechnology Reports 1:155-161.

Food and Agricultural Organization FAO (2005) Forest Resources Assessment: FAO Rome.

Farinola LA, Famuyide OO, Adebayo O, Awe F, Adedokun FT (2013). Overview of the link between green economy and sustainable rural livelihood in Nigeria. FAN Conference, pp 659-668.

FORMECU (1991). Forestry Plantation Development in Nigeria by 1990 Formecu/stat/publication no. 14, Ibadan, Nigeria.

Gostin I (2008). Effects of different plant hormones on Salvia officinalis cultivated in vitro. International Journal of Botany 4:430-436.

Handro W, Floh EJ (2001). Neo-formation of flower buds and other morphorgenetic responses in tissue culture of Melia azedarach. Plant Cell, Tissue and Organ Culture 64:73-76.

Husain MK, Ani M, Shahzad A (2008). In vitro propagation of multipurpose leguminous tree Pterocarpus marsupium Roxb. using nodal explants. Acta Physiologiae 30:353-35.

Isikalan C, Akbas F, Namli S, Basaran D (2010). Adventitious shoot development from leaf and stem explants of Amygdalus communis L. cv. 'Yaltunski'. Plant Omics Journal 3(3):92-96.

Jain SM, De Klerk GJ (1998). Somaclonal variation in breeding and propagation of ornamental crops. Plant Tissue Culture and Biotechnology 4:63-75.

Jiménez VM (2001). Regulation of in vitro somatic embryogenesis with emphasis on the role of endogenous hormones. Revista Brasileira de Fisiologia Vegetal 13:196-223.

Kahl G (1983). Wound repair and tumor induction in higher plants. In: Akazawa T, Imasei H (Eds). The new frontiers in plant biochemistry. Japan Scientific Society Press/ Martinus Nijhoff/ Dr. Junk W Press, Tokyo and the Hague, pp 193- 216.

Ladipo D (2010). The state of Nigeria's forest. International Institute of Tropical Agriculture (IITA), Ibadan, Nigeria. www.r4dreview.org>issue4/

Lin J, Wu L, Liang J, Wang J (2010). Effect of different plant growth regulators on callus induction in Catalpa bungei. African Journal of Agricultural Research 5(19):2699-2704.

Malik SK, Kalia RK, Chaudhury R (2010). In vitro regeneration of Garcinia indica using leaf explants. Indian Journal of Plant Physiology 15:262-266.

Martin KP (2002). Rapid Propagation of Holostemma adakodien Schult., a rare medicinal plant through axillary bud multiplication and indirect organogenesis. Plant Cell Reports 21:112-117.

Murashige T, Skoog F (1962). A revised medium for rapid growth and bioassays with tobacco tissue cultures. Physiologia Plantarum 15:473-495. 
Naval MM, Llacer G, Badenes ML, Glordani E (2009). Adventitious shoot regeneration from leaf explants of the persimmon (Diospyras kaki Thumb.) cv 'Rojo Brillante'. Acta Horticulturae 833:183-186.

Niembro-Rocas A (2003). Enterolobium cyclocarpum (Jacq.) Griseb. In: Vozzo JA (Ed). Tropical tree seed manual. US Department of Agriculture Handbook 721. USDA Forest Service, Washington, DC.

Ntui VO, Uyoh EA, Urua IS, Ogbu U, Okpako EC (2012). Regeneration of Parkia biglobosa Benth.: an important tree species of Africa. Journal of Microbiology and Biotechnology Research 2(1):169-177.

Odediran FA, Arabomen O, Akanbi FS, Obafunsho OE, Wahab WT (2013). Deforestation: causes and consequences on the environment and resource sustainability in Nigeria. Proceedings of the FAN conference, pp 484-492.

Pérez-Francés JF, Valdés F, Msrtín R (1995) Callus induction and culture from explants of Erysimum scopariumin a growth regulator-free medium. Plant Cell, Tissue and Organ Culture 43(3):223-228.

Rahman SM, Hossain M, Biswas BK, Joarder OI, Islam R (1993). Micropropagation of Caeselpina pucherima through nodal bud culture of mature tree. Plant Cell, Tissue and Organ Culture 32:363-365.

Razdan MK (2003). Organogenesis. In: Introduction to plant tissue culture. $2^{\text {nd }}$ Ed. Science Publishers Inc. Enfield (NH), USA, Plymouth UK pp 71.

Renukdas N, Manoharan M, Garner JO (2010). In vitro propagation of pecan (Carya illinoinensis (Wangenh) R. Koch). Plant Biotechnology 27:211- 215.

Rincón F, Oberto A, León-De Pinto G (2005). Functionality of Enterolobium cyclocarpum gum in the preparation of liquid low-fat yogurt. Revista Cientifica-Faculdad de Ciencias Veterinarias 15(1):83-87.

Rincón F, León-De Pinto G, Beltrón O (2006). Behaviour of a mixture of Acacia glomerosa, Enterolobium cyclocarpum and Hymenaea courbaryl gums in ice cream preparation: note. Food Science and Technology International 12(1):13-17.

Rita I, Floh, EIS (1995). Tissue culture and micropropagation of Cuphea ericoides, a potential source of medium-chain fatty acids. Plant Cell, Tissue and Organ Culture 40:187-189.

Rocha SC, Quoirin M (2004). Calogênese e rizogênese em explants de mogno (Swietenia macrophylla King) cultivados in vitro. Ciência Florestal 14:91-101.

Sadegh M, Rosna MT, Arash K, Jamilah SY (2012). Induction of different types of callus and somatic embryogenesis in various explants of Sainfoin (Onobrychis sativa). Australian Journal of Crop Science 6(8):1305-1313.

Sajeevan R Singh SJ, Nataraj KN, Shivanna MB (2011). An efficient in vitro protocol for multiple shoot induction in Mulberry, Morus alba L. variety VI. International Research Journal for Plant Science 2(8):254-261.

Salvi ND, Singh H, Tivarekar S, Eapen S (2001). Plant regeneration from different explants of Neem. Plant Cell, Tissue and Organ Culture 65:159-162.

Sayer AJ, Harcourt CS, Collins MN (2010). The conservation atlas of tropical forest Africa. Macmillan Publisher Ltd, ISBN 033337757-4, pp 9-230.

Shasthree T, Imran MA, Mallaiah B (2009). In vitro rooting from callus cultures derived from seedling explants of Erythrina variagata L. Current Trends in Biotechnology and Pharmacy 3(4):447- 452.

Sugla T, Purkayastha J, Krant, KS, Solleti SK, Sahoo L (2007). Micropropagation of Pongamia pinnata through enhanced axillary branching. In vitro Cellular and Developmental Biology in Plant 43(5):409-414.

Standley PC, Steyermark JA (1946). Enterolobium in flora of Guatemala. Fieldiana: Botany 24(5):32-34.

Thomas TD, Shankar S (2009). Multiple shoot induction and callus regeneration in Sarcostemma brevistigma Wight and Arnott, a rare medicinal plant. Plant Biotechnology Reports 3(1):67-74.

Tibok A, Blackhall NW, Power JB, Davey (1999). Optimized plant regeneration from callus derived from seedling hypocotyls of Eucalyptus urophylla. Plant Science 110(1):139-145.

Trevor AT, Indra, SSH (1990). Special problem and prospects in the propagation of woody species. In: Plant aging Springer, Boston, MA, pp 67-74.

United Nation Environmental Programme: UNEP (2003). http://www.uneporg/DEWA/Africa/docs/en/aeo

UN-REDD (2013). The State of Nigeria's Forest. www.unredd.org/aboutUNREDDprogramme/National Programme/Nigeria/tabid/199/default.aspx

Uphof JC (1959). The dictionary of economic plants. Weinheim, J Cramer.

Venkatachalam P, Geetha N, Khandelwal A, Shaila MS, Sita GL (1999). Induction of direct somatic embryogenesis and plant regeneration from mature cotyledon explants of Arachis hypogaea L. Current Science 77:269-273. 
Vidoz ML, Quesenberry KH, Real D, Gallo M (2012). Plant regeneration of Lotononis bainesii Baker (Fabaceae) through cotyledon and leaf culture. African Journal of Biotechnology 11(41):9724-9731.

Xie D, Hong Y (2001). In vitro regeneration of Acacia magnum via organogenesis. Plant Cell, Tissue and Organ Culture 66:167-173.

Xiaomei Liu, Pijut PM (2008). Plant regeneration from in vitro leaves of mature black cherry (Prunus serotina). Plant Cell, Tissue and Organ Culture 94:113-123.

Ye X, Chen y, Li J, Yu X, Feng J, Zheng X (2012). Callus induction and adventitious shoot regeneration in Zizyphus jujuba Mill. 'Huizao'. African Journal of Biotechnology 11(16):3888-3894.

Yin Z, Zhiqi Z, Jianjun Z (2001). Use of hymexazol (HMI) in rapid propagation of Albizia julibrissin Durazz. Acta Agriculturae Shanghai 17:31-34.
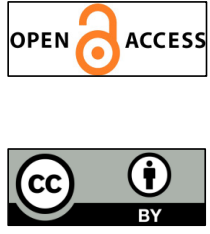

The journal offers free, immediate, and unrestricted access to peer-reviewed research and scholarly work, due SHST supports to increase the visibility, accessibility and reputation of the researchers, regardless of geography and their budgets. Users are allowed to read, download, copy, distribute, print, search, or link to the full texts of the articles, or use them for any other lawful purpose, without asking prior permission from the publisher or the author.

License - Articles published in Notulae Scientia Biologicae are Open-Access, distributed under the terms and conditions of the Creative Commons Attribution (CC BY 4.0) License.

(c) Articles by the authors; SHST, Cluj-Napoca, Romania. The journal allows the author(s) to hold the copyright/to retain publishing rights without restriction. 